DANIEL JUSTEL VICENTE

\title{
ABANDONOS INFANTILES EN LA LITERATURA CUNEIFORME Y BÍBLICA
}

\section{Resumen}

En el mundo de la mitología, los abandonos de niños fueron un tópico literario recurrente en prácticamente todas las civilizaciones antiguas. Sin embargo, el fenómeno de abandonar niños no debe circunscribirse solamente al plano mítico, ya que sin duda tal práctica se llevaría a cabo con relativa asiduidad. El objetivo de este artículo es presentar y analizar las principales fuentes que la literatura cuneiforme y bíblica (entre el III y el I milenio a. C.) ofrece para el estudio de las exposiciones infantiles. Con este propósito atenderemos a las principales características de los diferentes tipos de documentos, presentando, cuando sea conveniente, la traducción de ejemplos paradigmáticos para cada caso. La puesta en común de este corpus sobre abandonos infantiles en el Oriente antiguo ayudará a comprender mejor el mitema del niño expósito en las leyendas antiguas, así como el trágico trasfondo socio-económico por el que muchos padres optarían por abandonar sus hijos a su suerte.

Palabras clave: Abandonos. Infancia. Mesopotamia. Biblia. Acadio. Sumerio. Cuneiforme.

\section{Introducción}

En el mundo de la mitología, los abandonos de niños fueron un tópico literario recurrente en prácticamente todas las civilizaciones antiguas. Estas construcciones tradicionales, generalmente con final feliz para el abandonado, tenían como principal objetivo justificar la elección divina de este. Gracias a esta ayuda sobrenatural, el expósito se presentaba desde poco después de su nacimiento como un sujeto con una velada o abierta 
relación con la divinidad, frecuentemente con capacidades de liderazgo y llamado a realizar grandes empresas auspiciado por los dioses.

Cuenta Pausanias (siglo II d. C.) que Perseo fue arrojado junto con su madre Dánae al mar en un cofre de madera, para luego ser salvado en la isla de Sérifos por Dictis. También desencadenados los acontecimientos por la profecía de un oráculo, el rey de Tebas, Layo, padre de Edipo, mandó matar a su hijo, quien finalmente fue colgado de un árbol, atado por los pies y salvado por un pastor. Es asimismo un pastor, Fáustulo, quien, según la tradición romana, encontró a Rómulo y Remo tras ser amamantados por la loba Luperca, habiéndolos esta encontrado anteriormente en una canasta junto al Tíber. Por su parte, el historiador Pompeyo Trogo (siglo I a. C.) nos informa sobre el abandono del rey de Tartessos, Habis, quien fue amamantado por animales salvajes y después sentó las bases para consolidar su reino. El mundo clásico cuenta con otros muchos ejemplos similares.

Sin embargo, el fenómeno de abandonar niños en todas estas realidades históricas no debe circunscribirse solamente al plano mítico, ya que sin duda tal práctica se llevaría a cabo con relativa asiduidad. Las fuentes que nos informan sobre la exposición real de recién nacidos son diversas en su naturaleza documental, y cada sociedad antigua enfocaba la cuestión de una manera distinta y moralmente definida. Así, al tratar la limitación de la natalidad en la Atenas clásica, Polibio (siglo II a. C.) evidencia que el recurso a la exposición de neonatos debía de ser frecuente ${ }^{1}$, práctica para la que contamos con paralelos anteriores que aluden a la cuestión también en obras teatrales griegas ${ }^{2}$. Por su parte, Dionisio de Halicarnaso (siglo I a. C.) nos habla de una ley promulgada por el mismo Rómulo en la que permitía abandonar niños mutilados o deformes ${ }^{3}$, fenómeno asimismo atestiguado en la ley de las XII Tablas ${ }^{4}$. Por contra, y tanto en época helenística como romana, Diodoro Sículo (siglo I a. C.) afirma que los judíos eran conocidos por no practicar el infanticidio ${ }^{5}$, algo que también para los germanos de la época, según Tácito (siglos I-II d. C.), se equiparaba con un crimen ${ }^{6}$.

1 Cf. PolıBı, Historias XXXVII, 17, 7.

2 Tanto en comedias (p. e. Aristófanes, Las nubes 530-532) como en tragedias (p. e. Aristófanes, Las Tesmoforias 505-516). Sobre estas cuestiones, cf. el reciente trabajo de Rocher 2012. Sobre la exposición de niños en la Grecia clásica, cf. especialmente GERMAIN 1975.

3 Dionisio de Halicarnaso, Historia antigua de Roma II, 15.

${ }^{4}$ Ley de las XII Tablas IV, I. Cf. asimismo CICERón, De legibus III, 8, 19.

5 Diodoro Sículo, Biblioteca histórica XL, 3.

6 TÁcIto, Germania XIX. 
Todos estos ejemplos, pequeña selección de infinidad de casos atestiguados, ponen de manifiesto que en el mundo antiguo la práctica de abandonar niños era común, e incluso se llevaba a cabo en algunos ámbitos con cierta naturalidad y bajo parámetros legales permitidos. Para analizar este fenómeno en las sociedades clásicas contamos con multitud de referencias de autores contemporáneos, lo que se traduce en la proliferación de trabajos consagrados a la cuestión en la historiografía moderna. El caso del Próximo Oriente antiguo, entendido este como los ámbitos cuneiforme y bíblico, es de algún modo distinto, puesto que las menciones a tal práctica no son tan frecuentes como en el mundo clásico. Sin embargo, sí encontramos referencias cuneiformes y bíblicas al fenómeno del abandono de niños tanto a través de casos mitológicos como de práctica cotidiana. De hecho, las exposiciones infantiles en ríos, bosques o montañas, al igual que las comentadas más arriba, también se atestiguan en ejemplos próximo-orientales comentados más adelante $(\$ 2.1)$. ¿Hasta qué punto esta tradición mesopotámica guardaría relación con el posterior desarrollo en las sociedades clásicas? Además, y aunque en una proporción menor en comparación con Grecia o Roma, en el antiguo Oriente están atestiguados asimismo varios casos prácticos de abandonos de niños.

El objetivo de este artículo es presentar y analizar las principales fuentes que la literatura cuneiforme y bíblica ofrecen para el estudio de las exposiciones infantiles. El marco temporal es, por consiguiente, amplio, estando comprendido entre el III y el I milenio a. C., y emplazado geográficamente en las regiones mesopotámicas y la costa siro-palestina. Con este propósito atenderemos a las principales características de los diferentes tipos de documentos, presentando, cuando sea conveniente, la traducción de ejemplos paradigmáticos para cada caso. La puesta en común de este corpus sobre abandonos infantiles en el Oriente antiguo ayudará a comprender mejor el mitema del niño expósito en las leyendas antiguas, así como el trágico trasfondo socio-económico por el que muchos padres optarían por abandonar a sus hijos a su suerte.

\section{Fuentes de abandonos infantiles en el Próximo Oriente antiguo}

Como se ha apuntado, las fuentes cuneiformes y de la Biblia sobre exposiciones infantiles son dispares en su cronología, procedencia geográfica y naturaleza textual. Es lógico pensar que una práctica como la de abandonar niños, algo que generalmente se llevaría a cabo en la más estricta in- 
timidad, no nos haya llegado en un formato documental definido, como sí ocurre con otros textos cuneiformes tipificados: herencias, arreglos matrimoniales, ventas de propiedades, etc. Por tanto, es lícito afirmar que la cuestión aquí analizada se presta a una disgregación literaria en sus formas, si bien todos estos textos nos informarán sobre el mismo fenómeno, sea mítico o real. A continuación se expone una sencilla clasificación en la que tienen cabida los principales documentos de abandonos infantiles del Próximo Oriente antiguo conocidos hasta la fecha.

\subsection{Textos mitológicos y literarios}

Este tipo de documentación está presente tanto en textos cuneiformes como en el Antiguo Testamento. Entre las evidencias que nos hablan directamente sobre abandonos míticos de niños se encuentra, por ejemplo, el caso del rey Sargón de Acad, personaje situado en la segunda mitad del III milenio a. C. y que, según la leyenda, fue abandonado en un río dentro de un canasto de juncos (cf. § 4.2). Encontramos este mitema en el libro del Éxodo con el abandono de Moisés en el Nilo. Hay que señalar asimismo la existencia de una referencia similar con el caso de Ciro II, rey de Persia, cuya infancia es relatada por Heródoto (siglo v a. C. $)^{7}$.

A estos y otros paralelos deberemos añadir ciertos casos que nos informan indirectamente sobre abandonos de niños. Un buen ejemplo es el pasaje presentado en el libro de Ezequiel (16,1-7), donde encontramos una alegoría describiendo la relación de Yahvé con Jerusalén en la que esta última es comparada con una niña expósita, "revolcada en su sangre" (cf. § 3.4) y posteriormente rescatada. La terminología empleada evidencia que el autor del libro de Ezequiel conocía bien la tradición legal mesopotámica, ya que utiliza expresiones y términos para conferir una forma concreta a su creación literaria ${ }^{8}$.

7 Cf. Historia I, 108-113. Según Heródoto, el rey medo Astiages tuvo un sueño en el que se profetizaba que su nieto Ciro le derrocaría. El monarca ordenó a su sirviente Harpago deshacerse de Ciro, pero Harpago, a instancias de su esposa, se negó a realizar tal atrocidad, delegando su cometido en un pastor al que le aconsejó abandonar al niño "en la parte más desolada de las montañas, para que muera lo más pronto posible" (Historia I, 110). Heródoto cuenta con detenimiento el desarrollo de los acontecimientos, que lógicamente presentan un final feliz para el futuro Ciro el Grande.

8 Sobre este pasaje del libro de Ezequiel, cf. especialmente Cogan 1968 y MaLuL 1990. 


\subsection{Series lexicales mesopotámicas}

También llamadas "series gramaticales", este tipo de documentos cuneiformes plasman fórmulas normalizadas, generalmente de carácter jurídico, y que servían como ejercicios escribales. La cronología de las dos series más destacadas, ana ittǐš y HAR-ra hubullum, ha sido debatida por varios autores, sin bien parece haber un consenso en situarlas en el siglo XVIII a. C., tras la toma de Nippur por Hammurapi, pero antes de la promulgación de su Código $^{10}$.

Aunque las numerosas expresiones que encontramos en las series lexicales no tengan una traducción real en casos concretos, su importancia viene dada por el empleo de dichas fórmulas, en sumerio con su traducción acadia, en numerosos textos posteriores sobre abandonos infantiles, tanto legislativos como de práctica legal. Su valor a nivel filológico es, por tanto, innegable, y constituyen una fuente básica para comprender la evolución formulística de los demás documentos de exposiciones de niños.

De naturaleza paralela, si bien no constituyen listas lexicales propiamente dichas, debemos hacer una breve referencia a los conocidos como "casos modelo". Son documentos que, sin ser de práctica legal, presentan compendios de cláusulas contractuales con terminología específica, por lo que su valor filológico será asimismo importante ${ }^{11}$.

9 Como las denomina Meissner $(1982,16)$ al referirse a los elementos lingüísticos presentes en las series lexicales.

10 Teniendo en cuenta la probable contemporaneidad de la serie serie HAR-ra hubullum, DAVID $(1927,5)$ dató la serie ana ittišu en la Dinastía de Ur III (2112-2004 a. C.), mientras que LANDSBERgER $(1937$, II) interpretó su origen como más tardío, en la época de Hammurapi (siglo XVIII a. C.). Por su parte, DrIVER y MILES $(1952,25$ ) se mostraron de acuerdo con David, calificando de "conjetural" el datar la lista en el reinado de Hammurapi. Aun así, la mayoría de autores, siguiendo a Landsberger, la sitúan en el siglo XVIII a. C. Cf., por ejemplo, LEWY y LEWY 1942/1943, 89 y n. 355, ButZ 1980, 477a, FLeISHMAN 2005, 492, o, a la luz de CBS 11324, ejercicio escolar editado recientemente, KLEIN y SHARLACH 2007, 3. Nosotros generalizaremos la datación de la serie ana ittišu contextualizándola en el período paleobabilonio lesto es, en la primera mitad del II milenio a. C.J, aunque siendo conscientes de que su tradición textual se remontaría sin duda al III milenio a. C. Sobre estos ejercicios de escuela, cf. Landsberger 1937, 1957, 1958, 1959; Cavigneaux 1980/1983; Michel 2001.

11 Un buen ejemplo en este sentido lo constituye el texto escolar de época paleobabilonia CBS 11324 (cf. KLEIN - ShARLACH 2007, 4-9). Para el caso de un niño que es adoptado tras ser arrojado a un horno, véase asimismo el recientemente editado ZA 101 § 44 (cf. SpadA 2011, 241-242). 


\subsection{Textos legislativos}

Algunos códigos legislativos ofrecen también varias disposiciones sobre adopciones de niños expósitos. El primero cronológicamente es el artículo 20 de las leyes del rey Lipit Ištar (1934-1924 a. C.): "Si un hombre rescata a un niño de un pozo, deberá [tomar sus] pies [y sellar una tablilla con la medida de sus pies (como identificación)]" ${ }^{12}$.

El posterior Código de Hammurapi (siglo XVIII a. C.) trata idéntica cuestión, si bien la expresión empleada para evidenciar el supuesto de niño abandonado es esta vez ina mêšu: CH 185: "Si un hombre adopta a un niño ina mêšu y lo cría, ese niño no podrá ser reclamado" ${ }^{13}$. Todo apunta a que la fórmula ina mêšu, analizada más adelante (cf. § 3.4), hace referencia al líquido amniótico del menor nada más nacer, aspecto relacionado con la referencia a la sangre del pasaje de Ezequiel (\$ 2.1).

Tras esta época paleobabilónica no encontramos referencias a abandonos de niños en documentos legislativos. Aun así, tanto la terminología empleada como la relación entre adopción y abandono tendrán su traducción en casos de práctica legal (cf. § 2.4).

\subsection{Contratos}

Los textos legales también nos informan acerca de los abandonos de niños en el Oriente antiguo. Especialmente significativos son los contratos en los que se plasma la adopción de un niño expósito por parte de un adulto. Esta dualidad es una constante en la documentación mesopotámica y siria, apreciándose dos fases claramente diferenciadas jurídica y estructuralmente:

1) Un niño es abandonado generalmente por sus padres biológicos, y no tiene capacidad de salvación ${ }^{14}$.

2) Un adulto actúa conforme a la legalidad y adopta al niño, poniéndolo de manifiesto mediante expresiones recurrentes comunes con las demás adopciones ${ }^{15}$.

12 Para LLI 20 hemos seguido la restitución de Rотн $(1997,29)$, basada en la serie ana ittišu (1997, 352) (al respecto, cf. MoLINA 2000, 88 y 9522).

${ }^{13} \mathrm{CH}$ 185: šum-ma a-wi-lum șe-eh-ra-am i-na me-e-šu a-na ma-ru-tim il-qé-ma úr-ta-ab-bi-šu tar-bi-tum ši-i ú-ul ib-b̆a-aq-qar.

14 Esta primera fase (es decir, el abandonol presenta generalmente fórmulas sobre exposiciones infantiles que veremos más adelante (cf. § 3.1).

15 Sobre las fórmulas de adopción en el Oriente antiguo, cf. PAUL 1979/1980. Para el caso de las adopciones infantiles, cf. Justel 2012a, 105-107. 
A lo largo de las siguientes páginas mostraremos hasta qué punto la información expuesta como abandonos de niños se correspondía con dicho fenómeno, o si se trataría, por el contrario, de casos de empleo de terminología específica con un trasfondo más bien jurídico.

\subsection{Cartas}

La correspondencia entre cargos ligados a instituciones, como funcionarios o incluso reyes, constituye una fuente esencial para el acercamiento a las relaciones diplomáticas e interpersonales de las épocas. Para el Próximo Oriente antiguo contamos con miles de misivas que presentan temas realmente variados, desde aspectos burocráticos hasta personales. La singular carta ARM 643 del archivo de Mari (siglo XVIII a. C.), presentada más adelante ( $\$ 4.1)$, nos informa sobre el abandono de un menor en trágicas y oscuras circunstancias. Se trata del documento epistolar más gráfico y explícito que conocemos a lo largo de toda la documentación del Oriente antiguo sobre la cuestión de las exposiciones infantiles.

\section{Terminología en abandonos de niños}

3.1. Documentos sumerios y acadios de diversa tipología plasman el acto del abandono del niño mediante fórmulas predeterminadas, cristalizadas ya desde finales del III o principios del II milenio a. C., como se aprecia en la siguiente tabla, con las principales expresiones de abandono de niños en las series lexicales ana ittišu (MSL I) y HुAR-ra ḩubullum (MSL V):

\begin{tabular}{|c|c|c|c|}
\hline & Sumerio & Acadio & Español \\
\hline MSL I, 3 III: 34s & $\begin{array}{l}\text { ka.ur.[zí]r.ta ba. } \\
\text { an.[da].kar }\end{array}$ & $\begin{array}{c}i-n a \text { pi-i kal-bi e-ki- } \\
i m-s ̌ s\end{array}$ & $\begin{array}{l}\text { "Lo ha rescatado de la } \\
\text { boca del perro" }\end{array}$ \\
\hline MSL V 50: 5-6 & $\begin{array}{l}\text { ka.ur.ku.a.ni.šè } \\
\text { ba.an.da.kar }\end{array}$ & i-na pi-i kal-bi e-kim & $\begin{array}{l}\text { "Ha sido rescatado de } \\
\text { la boca del perro" }\end{array}$ \\
\hline MSL I, 3 III: 32 & túl.ta.pàd.da & $i$-na bur-ti a-tu-šu & $\begin{array}{l}\text { "Ha sido hallado en } \\
\text { un pozo" }\end{array}$ \\
\hline MSL V 50: 3 & pú-ta pà-da & $i$-na bur-ti a-tu & $\begin{array}{l}\text { "Ha sido hallado en } \\
\text { un pozo" }\end{array}$ \\
\hline MSL I, 3 III: 33 & sil.t[a ba.an.t]u.ra & i-na su-qí šu-ru-ub & "Tomado de la calle" \\
\hline MSL V 50: 4 & síl-ta ì-TU-ra & i-na su-ú-qí šu-ru-ub & "Tomado de la calle" \\
\hline
\end{tabular}


Expresiones como "arrojar a la boca del perro", "a un pozo" o "a la calle" constituyen sin duda actos simbólicos con los que se subraya la imposibilidad de que el expósito sobreviviera, a menos que apareciera un salvador ${ }^{16}$. Este se presenta generalmente como el adoptante del niño abandonado, y es el que lo "salva de la boca del perro", lo "toma de un pozo" o lo "levanta de la calle".

3.2. Así, apreciamos dos tipos de verbos para sendas acciones de "abandonar" y "salvar". Para el primer caso constatamos verbos acadios como nasāku, "arrojar" (Nbk 439, 3); nadû̀ ${ }^{17}$, "tirar" (CT 13 42, 6); ezēbu, "dejar, abandonar" (MDP 23 288, 9), o șalû, "arrojar" (E6 256, 9) ${ }^{18}$. Todos estos términos, si bien expresan un acto físico, se referirán realmente a la acción jurídica de "rechazar". Los padres naturales se desentienden de tal forma de su hijo mediante su abandono, no solo a nivel de cuidados básicos (alimento, vestido, etc.), sino también legal.

El segundo acto es el de la adopción, por el que el padre adoptivo se hace con el niño tras el abandono ${ }^{19}$. Para ello se emplean asimismo distintos verbos, algunos también muy gráficos: našû, "levantar, cuidar" (Nbk

16 En la misma línea, cf. CASSIN 1952, 119, n. 1.

17 Sobre la equivalencia del verbo acadio nadû en hebreo bíblico, cf. § 4.1.

18 Apréciese que la voz Š de șalû en época medio-asiria adquiere el sentido genérico de "abortar" (AHw 1077a: "Leibesfrucht abwerfen lassen". Cf. CAD Ș 71b d, sub șalā'u), fenómeno sin duda relacionado con los abandonos de niños.

19 La creación del contrato de adopción o de otro tipo no es cuestión baladí, puesto que el simple hecho de recoger a un niño abandonado no confiere automáticamente un tipo de filiación legítima o una existencia legal del expósito. Es interesante en este sentido en el texto neobabilonio VAS 6 116. Un documento anterior ( Nbn 990) presenta el caso de la mujer Șiraya, que es dada en matrimonio a Nabûnâdin-šumi, y entre la dote aportada hay tierras, bienes muebles y dos esclavas. Una de ellas es Šēpîtaya, objeto principal del posterior VAS 6 116. En este texto se menciona que Șiraya "levantó [a Šēpîtaya] de la calle y la crió" (ll. 7-8: ul-tu su-ú-qu / ta-šá-am-ma tu-ra-bu-úl, puesto que la sirvienta fue en su día abandonada. Estas afirmaciones fueron leídas en público, ante testigos, creándose entonces la existencia legal de Šēpîtaya y justificando la posesión de la esclava por parte de Șiraya y Nabû-nâdin-šumi. Así, y tomando como ejemplo el momento anterior a la creación de VAS 6 116, en palabras de JoANNĖs (1989), se puede afirmar que “ce status d'enfant recueilli ne permettait pas à Șiraia ni à son époux Nabû-nâdin-šumi de justifier de leur droit de propriété sur Šèpîtaia". Si bien es posible que VAS 6116 no constituya una verdadera adopción tras el abandono, sino la confirmación del estatus de esclava de Šēpîtaya (en la línea de SAN Nicolò 1930, 450), el documento muestra claramente que tras la exposición y salvación de un abandonado se debía crear un vínculo y existencia legal del mismo, careciendo en el intervalo de realidad jurídica alguna. Sobre estas cuestiones, cf. SAN Nicolò 1930; ROTH 1989, 71-73; JoANnÈs 1989; Dandamaev 2009, 103. 
439, 4; VAS 6 116, 820); šaqû, "levantar"; leqû, "tomar", "adoptar" (CT 52 103, 16" ${ }^{21}$; rubbû / rabû, "criar, educar" (MKGH 4, 422), o lamādu, "reconocer" (E6 256, 11). Mediante el empleo de estos verbos se subraya la naturaleza redentora del acto por parte de los padres adoptivos, quedando la adopción completamente justificada y a su vez evitando futuras reclamaciones $^{23}$.

3.3. En ocasiones encontramos este tipo de terminología en los propios nombres de los abandonados o en referencias a dichos sujetos. Así, constatamos antropónimos como Ša-pî-kalbi ("el de la boca del perro") ${ }^{24}$, Sūqā'a ("el / la de la calle") ${ }^{25}$, Aba-lā-idi, ("no conozco a mi padre") ${ }^{26} \mathrm{o}$ É.A.BA-ul-īšu ("no tengo casa paterna") ${ }^{27}$. Otros textos aluden a personas calificadas como "el que no tiene padre ni madre" ( ̌̌a aba u umma lā ǐŝû),

20 VAS 6 116, 8: ta-šá-am-ma. Sobre esta forma del verbo našû, cf. JoANNĖs 1989, 82, n. 2.

${ }^{21}$ En este contexto se emplea frecuentemente la versión sumeria de leqû bajo la forma ŠU BA.AN.TI lvéase un ejemplo en un texto paleobabilonio de abandono y adopción de niño en YOS 12331,7$)$.

22 Para este texto, cf. Franke - WiLhelm 1985.

23 Sobre la relación entre las fases de abandono y adopción en este tipo de textos, cf. Fleishman 2001, 401-402. Un texto en el que se aprecian claramente los dos actos legales de abandonar y salvar, empleándose terminología similar, pero con distinto uso de verbos y preposiciones, es el neobabilonio Nbk 439. En él la mujer soltera Șiraya "arrojó a su hijo a la boca del perro" (Il. 2-3: DUMU- 「 šú 1 a-na / [pii] kal-bi ta-as-su-ku). El acto de salvación está representado por la misma imagen, pero sin emplear la preposición a-na, “a, hacia”, sino ištu, "de” (sentido del inglés from, y en su variante neobabilonia ultu; véase la colación de WuNSCH [2003/2004, 219], contra la restitución de OpPenheIm [1943, 36]: [i]š (!)-tu): “[y] Nūr-Šamaš lo ha salvado [lit. "lo ha levantado", forma verbal de našû) de la boca del perro" (Il. 3-4: m[nū]r-dUTU / [u]l-tu pi-i kal-bi iš-šu-ú-u'-ma). Sobre esta cuestión, cf. OpPENHEIM 1943; WUNSCH 2003/2004, 220z. 3.

24 Sobre este antropónimo, cf. Stamm 1968, 320; Oppenheim 1943; Dandamaev 2009, 103-104.

25 Stamm 1968, 251.

26 Véase una variante de este nombre en el documento medio-babilonio inédito Ni. 5989 rev. ii' 9': aba-lā-idi.

27 Driver - Miles 1952, 3912. Al respecto, cf. en general Malul 1990, 105, $121^{67}$. Aunque probablemente el nombre del Moisés bíblico se trate en realidad de un antropónimo egipcio, teóforo, hay que mencionar el significado tradicional que se le ha conferido a dicho antropónimo, aceptado por autores como Flavio Josefo en sus Antigüedades judías. Ex 2,10 reza: “Cuando el niño hubo crecido, llevóselo a la hija de Faraón, la cual le tuvo como hijo y púsole por nombre Moisés, pues dijo: ¡En verdad que lo he sacado [מוהתיש] del agua!"” 


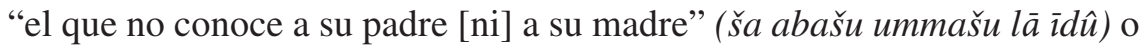
"el procedente de la boca del cuervo" (ina pî aribi ušaddi) ${ }^{28}$.

3.4. Mención aparte merecen dos expresiones acadias de abandonos infantiles que han sido debatidas a lo largo de la historiografía en la última centuria. En primer lugar, la construcción ina mêšum presente en al menos cuatro textos cuneiformes ${ }^{29}$, fue tradicionalmente traducida como "en su nombre", por el que el signo me fue interpretado como derivación del sumerio MU (ac. šumu, "nombre"). Yaron (1965, 171-173), sin embargo, propuso que la fórmula se entendiera como "en sus aguas" ${ }^{30}$, haciendo referencia al líquido amniótico. De esta forma quedaría patente que el expósito era realmente un recién nacido, abandonado completamente a su suerte y sin ninguna opción de sobrevivir por sí solo. Tras el trabajo de Yaron, la mayor parte de los autores se han mostrado de acuerdo con dicha interpretación ${ }^{31}$. El documento MDP 23 288, paleobabilonio redactado en acadio y procedente de Elam, confirma la lectura de Yaron, puesto que añade la cláusula u dāmēšu, "y [en] su sangre" 32 . El hecho de que el acto del nacimiento no

28 Para estas cuestiones, cf. especialmente MALUL 1990, 105, 121, n. 66. En este sentido es importante señalar el ejercicio escolar CBS 11324, probablemente procedente del Nippur paleobabilonio (KLEIN - SHARLACH 2007, 2). Se trata de un documento que presenta tres casos típicos de naturaleza jurídica familiar: al la adopción de un niño abandonado; b) la disputa de un hombre y su tío en torno a una herencia; c) la disputa de una herencia por dos hermanos. Si bien la primera parte (a) no constituye un caso real de abandono, sino un modelo de las fórmulas legales para referirse a tal cuestión (cf. 2.2), véanse las gráficas expresiones que sirven de apelativos del expósito recién nacido (ll. 1-7): “[Acerca de] un niño lactante, hallado en un pozo, salvado de la boca de un perro, sin padre, sin madre, sin hermana, sin hermano y sin hermano adoptivo: Ištar-rīmti-ilī le adoptó como hijo, y le puso el nombre de Ilī-tūram" ([dumu.nit]a .gaba / [túl.t]a 「 pà.da 7 ka ur.gi .ra.ta kar / [a] d.da nu.tuku ama nu.tuku nin, nu.tuku / šeš nu.tuku ù šeš.bar.ra nu.tuku / minanna-

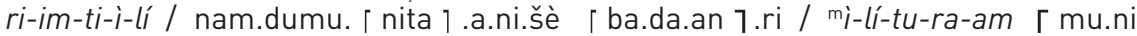
mu.sa ${ }_{4} 7$ ). Sobre esta primera parte de CBS 11324, cf. KLEIN - SHARLACH 2007, 4-9.

29 Véanse algunos ejemplos de la expresión ina mêšu en los textos CH 185; MDP 23388 (ina mêšu u damēšu); YOS 12 331, y CT 52 103. Sobre estos textos, en relación con dicha fórmula, cf. MaluL 1990, 106-113, y GarRoway 2014, 51-54.

30 Esto es, del acadio mû, "aguas".

${ }^{31}$ Cf. varias referencias a importantes ediciones del Código de Hammurapi que siguen la interpretación de Yaron en Justel 2012, 5, n. 15. Para otros autores que tras el trabajo de Yaron siguen entendiendo el texto como "en su nombre", cf., por ejemplo, Lara Peinado 1982, 113 (cf. Justel 2012a, 112, n. 40) y Colón 2001, 62.

32 MDP 23 288, 8-11: i-na me-e-šu / ù da-mé-šu i-zi-ib-šu-ma / [a]-na f.dtu-zi-damqa-at / [mu-še]-ni-iq-ti ta-ad-di-iš-šu-ma l"Ella lo ha abandonado en sus aguas y en su sangre, y lo ha entregado a Tuzi-damqat, la nodriza"). 
solo esté relacionado con el agua, sino también con la sangre ${ }^{33}$, hace que nosotros también optemos por la relación con el líquido amniótico. Interesante en este sentido es el paralelo bíblico mencionado en § 2.1 de Ez 16,17, sobre el que Malul (1990, 108-109) llama la atención. En él se presenta una alegoría de la infidelidad de Israel personificada en una niña pequeña que simboliza la ciudad de Jerusalén. Tras explicar el abandono de esa niña (vv. 1-5), Yahvé la salva (vv. 6-7): "Pero pasé junto a ti y te vi revolcada en

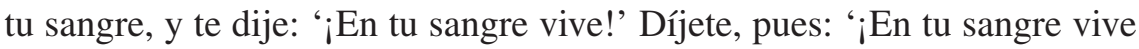
y crece!'” Este pasaje veterotestamentario será un paralelo más que confirme la interpretación de Yaron ${ }^{34}$.

La segunda expresión es šilip rēmim, fórmula común en algunos contratos mesopotámicos de adopción tras el abandono, especialmente de época paleobabilónica ${ }^{35}$. Mientras que Szlechter (1958, 3 y n. 1) tradujo la fórmula šilip rēmim de MAH 15951, 1, como "[arraché] à un tareau sauvage" 36, CAD Ș 232a (sub șuhāru 1b) la entiende como "[little boy] who had to be pulled out of the womb [at birth]" ${ }^{37}$. Tanto si se trata de "arrojado a un toro salvaje" como "arrojado del útero [al nacer]", el ejemplo de šilip rēmim se referirá sin duda a un abandono infantil ${ }^{38}$.

3.5. Por tanto, la terminología empleada en textos sobre abandonos infantiles nos informa sobre dicha práctica, principalmente a través de determinados antropónimos y expresiones recurrentes. Sin embargo, hay que ser cautos al analizar esas cuestiones, puesto que el vocabulario presente en dichos textos cuneiformes tiene más de simbólico que de práctica real. Así, es difícil imaginar a varios niños "arrojados a un pozo" o "a la boca de un perro", y sin duda alguna estas expresiones quedarían cristalizadas desde una época muy temprana para ser utilizadas en ejemplos de "casos modelo", práctica legal o series lexicales.

33 STOL 2000, 125.

34 Al respecto, cf. asimismo Swanepoel 1993; Gursky 2001, 85ss; Fleishman 2009 , 363.

35 Véanse algunos textos con dicha expresión en CT 48, 70; MAH 15951; BM 78811/78812; BE 6/1 58 (WILCKE 1981, 91).

36 Por tanto, del acadio rimu, "toro salvaje".

37 Esto es, del acadio rēmu, "útero".

38 Sobre esta expresión, cf. en general WILCKE 1981 y GARROWAY 2014, 93-98. 


\section{Tipos de abandonos infantiles y su continuidad entre el Próximo Oriente cuneiforme y la Biblia}

La literatura próximo-oriental antigua en torno a los abandonos infantiles muestra que, en la mayor parte de las ocasiones, el sujeto que abandona al niño no tiene como primera pretensión la eliminación del mismo. Así podemos diferenciar entre dos tipos básicos de exposiciones de infantes: en las que el abandono se presenta como el inexorable final del menor y en las que se atisba -y se desea con total seguridad- la inminente salvación del pequeño. En el presente subapartado analizaremos, de forma respectiva, algunos casos de ambas tipologías, presentando a posteriori algunos elementos de continuidad entre abandonos atestiguados en los mundos cuneiforme y bíblico.

4.1. Mucho menos presentes en las fuentes de cualquier tipo encontramos los abandonos de niños que presentan casos en los que el adulto pretende, deliberadamente, que el bebé muera. Incluso poseemos ejemplos en los que el final para el niño es trágico. En este sentido es interesante señalar el equivalente hebreo del acadio nadû, el verbo שלך, "arrojar". El libro de Ezequiel dice: "Fuiste [Jerusalén] arrojada [תשלכי] sobre la superficie del campo" (Ez 16,5). En el pasaje del libro del Éxodo sobre el abandono de Moisés también se emplea dicho verbo: "Luego Faraón dio orden a todo su pueblo, diciendo: 'A todo hijo que nazca de los hebreos le arrojaréis [תשליכהו al río"' (Ex 1,22). La intención de ambos pasajes, mediante el empleo del verbo שלך, es innegablemente deshacerse del abandonado.

En el mundo cuneiforme encontramos asimismo algún caso concreto de muerte deliberada de un niño. El mejor y seguramente más notorio ejemplo es una carta del archivo de Mari (siglo XVIII a. C.). En esta ocasión las evidencias del fallecimiento del menor son más que explícitas. El texto en cuestión, ARM 6 43, dice así:

Di a mi Señor: así dice Bahdî-Lîm, tu siervo: "Un niño lactante, nacido el año pasado, yacía enfrente del antiguo palacio, que se encuentra bajo la región inferior, cerca del canal. Este niño había sido cortado por la mitad: solo quedaban sus restos desde el pecho hasta la cabeza, pero no la cabeza, y no quedaba nada de él hasta los pies. Niño o niña, ¿quién lo puede saber? Del busto hasta la parte inferior no se conservaba nada de su cuerpo. El mismo día en el que llegó a mis oídos esta historia di las órdenes convenientes, y pregunté de forma incisiva a los jefes del barrio, a los maestros obreros y a los extranjeros domiciliados, pero ni el responsable del niño, ni su padre, ni su madre, ni persona al corriente del asunto se presentó ante mí" ${ }^{39}$.

39 Esta traducción se basa en las restituciones de DuRAND 2000, 236-237. Para profundizar en este texto, cf. KUPPER 1954, 67-69; KLímA 1975, 124-125; DuRAND 1987, 664. 
4.2. Aun con todo, y teniendo presentes fuentes similares a las expuestas, la mayor parte de los abandonos atestiguados en los ámbitos bíblico y cuneiforme poseen un final feliz para el expósito. En primer lugar, y contrariamente a lo visto con el verbo hebreo שלך, "arrojar", cuyo propósito es el de deshacerse intencionadamente del menor, encontramos el verbo שום , "poner", "colocar". El ejemplo bíblico más significativo en este sentido es de nuevo el relato de Moisés. Si bien el redactor podría haber empleado el verbo שלך al referirse al acto de arrojar al bebé en el Nilo, la intención de la madre de Moisés era innegablemente que se salvara, razón por la cual se elige un verbo determinado. El pasaje dice así: "Como no pudiese ocultarle [a Moisés] por más tiempo, cogió una cesta de papiro, la calafateó con betún y pez, colocó [ותשם] en ella al niño y la colocó en el juncal, a la orilla del Nilo" $\left(\right.$ Ex 2,3) ${ }^{40}$.

Como en el caso de la madre de Moisés, el objetivo de la mayor parte de los abandonos infantiles atestiguados para el Oriente cuneiforme era que el menor se salvara. Este deseo se aprecia, por ejemplo, en el hecho de que casi todos los abandonos atestiguados acaben con la adopción del niño (cf. § 2.4). El acto del abandono sería por tanto figurado, y la consiguiente adopción sería el final lógico de esta serie de eventos en los que el niño comienza por ser repudiado legalmente (abandono) para luego ser reconocido por una tercera parte (adopción). Un ejemplo similar al de Moisés lo encontramos en la historia del rey Sargón de Acad, cuya historia aparece relatada en documentos neoasirios y neobabilónicos:

Mi madre, gran sacerdotisa, me concibió y me dio a luz en secreto. Me puso en un cesto de juncos y selló con pez sus aberturas. Me depositó en el río, que no se alzó contra mí. El río me llevó hasta Akki, el escanciador de agua. Akki, el escanciador de agua, me sacó cuando hundía su cubo en el río. Akki, el escanciador de agua, me adoptó como su hijo y me crió ${ }^{41}$.

Como se ha visto ( $\$ 3.2$ ), las lenguas cuneiformes también presentan un amplio espectro en cuanto a los términos referidos a los actos de abandonar y salvar a los menores. La combinación de todos ellos será fructífera especialmente en la documentación acadia, proporcionando numerosos ejemplos tanto mitológicos como de práctica legal.

4.3. Por tanto, hallamos referencias paralelas a abandonos de niños tanto en el ámbito cuneiforme como en el bíblico. Ahora bien, ¿hasta qué punto se puede hablar de continuidad o de discontinuidad entre ambos

40 Cf. Cogan 1968 y Malul 1990. En el mismo sentido, para el mundo romano, cf. Sevilla Conde 2012, 203ss.

${ }^{41}$ Cf. el documento CT 13, planchas 42-43. 
corpora? Es evidente, en primer lugar, el paralelismo entre algunos relatos, como el del rey Sargón II y Moisés. El hecho de ser abandonado secretamente por la madre, colocado en una cesta en un río (Éufrates y Nilo respectivamente), encontrado y criado por un tercero, o incluso adquiriendo a la postre el rango de realeza, hace que nos encontremos sin duda ante un mitema común.

Por lo que respecta a otras referencias, se hace más complicado proponer un hilo conductor entre ambas realidades. La documentación cuneiforme es mucho más prolija en la cuestión de las exposiciones infantiles, con rica y variada terminología. Aun así, el elemento común entre los dos ámbitos se refiere al deseo general de que los niños sobrevivieran al abandono $^{42}$. Por último, mientras que la documentación cuneiforme sobre la cuestión presenta generalmente un motivo más bien jurídico (abandono como justificación a la posterior adopción), el relato veterotestamentario, evidentemente, hace más hincapié en el trasfondo religioso. Es Yahvé, y no el adoptante, el que salva al menor de una muerte segura. Esta perspectiva, presente en los ejemplos bíblicos comentados, se ve reflejada en otros versículos, como en Sal 27,10: "Si mi padre y mi madre me dejaren, Yahvé me acogerá". Además, los casos bíblicos responderán más bien a mitos o alegorías, no tanto ejemplos reales como los cuneiformes.

\section{Conclusiones}

Todo apunta a que las exposiciones infantiles fueron una práctica relativamente frecuente en el mundo próximo-oriental antiguo. La documentación bíblica, y más aún la cuneiforme, aborda la cuestión en numerosas ocasiones a lo largo de un corpus amplio en cronología y diversidad de géneros literarios (textos lexicales, cartas, contratos, leyes, relatos, etc.). Parece claro que las dos realidades condenaban tajantemente la práctica de abandonar niños, razón por la cual apenas hay atestiguados -no porque no se dieran- casos de abandonos o asesinatos de menores.

Estas sociedades próximo-orientales antiguas, en su diversidad, contemplaban al niño como el elemento más prometedor de la sociedad, y tanto leyes como documentos de práctica legal pretenden de una forma u otra

42 Evidentemente, hacemos referencia a los ejemplos atestiguados, ya que el acto de abandonar a un infante se podría llevar a cabo con relativa frecuencia, y solo documentos como el mariota ARM 6 43, estando más próximo al infanticidio que al abandono, hacen que nos percatemos de casos con final trágico. 
beneficiar al menor, al indefenso. Las expresiones que poseemos para afirmar dicha idea provienen de un elenco textual amplio, heterogéneo, en el que el hilo conductor no es otro que el deseo de que el infante no solo salga ileso tras el abandono, sino que realmente sea el beneficiado. A lo largo del artículo hemos explorado aspectos formales y temáticos relativos a exposiciones infantiles en el Oriente antiguo, aportando, cuando era necesario, ejemplos concretos que las fuentes ofrecen. Aun con las diferencias evidentes entre un corpus y otro, tanto en terminología como en temática -por ejemplo, la continua presencia de Yahvé en la Biblia en comparación con el casi perenne trasfondo jurídico, como elemento humano, en la Mesopotamia cuneiforme-, podemos afirmar que ambas realidades valoraban abiertamente a los niños como elementos clave de sus respectivas sociedades. La eliminación voluntaria del menor, al igual que el aborto, era contemplada no solo como un crimen con respecto al abandonado, sino hacia toda la sociedad, verdadera depositaria del valor del niño.

\section{Bibliografía}

Butz, K., 1980, "Landwirtschaft", RlA 6, 470-486.

Cassin, E.-M., 1952, "Symboles de cession immobilière dans l'ancien droit mésopotamien”, L’Année Sociologique, $3^{\mathrm{e}}$ série, Paris, 107-161.

Cavigneaux, A., 1980/1983, "Lexikalische Listen", RlA 6, 609-641.

Cogan, M., 1968, “A Technical Term for Exposure”, JNES 27 (1968) 133135.

Colon, A. R. (con A. P. Colon), 2001, A History of Children: A Sociocultural Survey Across Millennia, Westport.

Dandamaev, M. A., 2009, Slavery in Babylonia. From Nabopolassar to Alexander the Great (626-331 B C), Northern Illinois University (ed. rev. de la de 1984).

DAvid, M., 1927, Die Adoption im altbabylonischen Recht, Leipzig.

Driver, G. R. - Miles, J. C., 1952, The Babylonian Laws, vol. I. Legal Commentary, Oxford.

DURAND, J.-M., 1987, “La population de Mari”, MARI 5, 664-665.

—, 2000, Les documents épistolaires du palais de Mari, LAPO 18, Paris.

Fleishman, J., 2005, "Continuity and Change in Some Provisions of the Code of Hammurabi's Family Law", en Sefati, Y. et al. 2005, "An experienced scribe who neglects nothing”. Ancient Near Eastern Studies in Honor of Jacob Klein, Bethseda, 480-496.

—, 2001, "Child Maintenance in the Laws of Eshnunna", ZAR 7, 374-383. 
—, 2009, "Did a Child's Legal Status in Biblical Israel Depend upon his beign Acknowledged?", ZAW 121, 350-368.

FranKe, S. - Wilhelm, D., 1985, "Eine Mittelassyrische Fiktive Urkunde zur Wahrung des Anspruchs auf ein Findelkind", Jahrbuch des Museums für Kunst und Gewerbe Hamburg 4, 19-26.

Garroway, K. H., 2014, Children in the Ancient Near Eastern Household (Explorations in Ancient Near Eastern Civilizations 3), Winona Lake.

Germain, L. F. R., 1975, "L'exposition des enfants nouveau-nés dans la Grèce ancienne: aspects sociologiques", en L'enfant. Première partie: Antiquité - Afrique - Asie (Recueils de la Société Jean Bodin pour l'histoire comparative des institutions 35), Bruxelles, 211-246.

Gursky, M. D., 2001, Reproductive Rituals in Ancient Israel, New York.

JOANNÈs, F., 1989, šêpê ina țiț̣i šakânu, NABU 109, 81-82.

Justel, D., 2012a, "Adopciones infantiles en el Próximo Oriente Antiguo", en ID. (ed.), Niños en la Antigüedad. Estudios sobre la infancia en el Mediterráneo Antiguo, Zaragoza.

—, 2012b, "Some reflections on the age of adopted children and their adoptive parents at Nuzi", SCCNH 20, Winona Lake, 141-157.

Klein, J. - Sharlach, T. M., 2007, "A Collection of Model Court Cases from Old Babylonian Nippur (CBS 11324)", ZA 97, 1-25.

KLÍmA, J., 1975, "Le statut de l'enfant d'après les documents cunéiformes de Mari (Première moitié du $2^{\mathrm{e}}$ Millénaire avant J.C.)", en L'enfant. Première partie: Antiquité - Afrique - Asie (Recueils de la Société Jean Bodin pour l'histoire comparative des institutions 35), Bruxelles, 119-130.

KupPer, J. R., 1954, Correspondance de Bahli-Lim, ARM 6, Paris.

LANDSBerger, B., 1937, Die Serie ana ittišu, Roma, 1937.

-, 1957, The Series HAR-ra = hubullu, MSL 5 (tablillas I-IV), Roma.

- 1958, The Series HAR-ra = hubullu, MSL 6 (tablillas V-VII), Roma.

-, 1959, The Series HAR-ra = hubullu, MSL 7 (tablillas VIII-XII), Roma.

Lara Peinado, F., 1982, Código de Hammurabi, Madrid.

LEWY, H. - LEWY, J., 1942-1943, "The origin of the week and the oldest west asiatic calendar", HUCA 17, 1-152.

Malul, M., 1990, "Adoption of Foundlings in the Bible and Mesopotamian Documents. A Study of Some Legal Metaphores in Ezekiel 16.17", JSOT 46, 97-126.

MeISSner, B., 1982, "Studien zur serie ana ittišs", ZA 7, 16-32.

Michel, C., 2001, "Listes lexicales", en JoAnnès, F. (ed.), 2001, Dictionnaire de la Civilisation Mésopotamienne, París, 475-476.

OPPENHEIM, L., 1943, “Assyriological Gleanings I”, BASOR 91, 36-37.

Paul, S. M., 1979-1980, "Adoption Formulae: a study of cuneiform and biblical legal clauses", MAARAV 2/2, 173-185. 
SAN Nicolò, M., 1930, "Über Adoption und die Gerichtsbarkeit der mârbânî im neubabylonischen Rechte", ZSS 50, 445-455.

SAncho Rocher, L., 2012, "Teкvototía. Estrategias de natalidad en las ciudades griegas de época clásica”, en Justel 2012a, 163-198.

Sevilla Conde, A., 2012, "Morir ante suum diem. La infancia en Roma a través de la muerte", en Justel 2012a, 199-233.

Stol, M., 2000, Birth in Babylonia and the Bible. Its Mediterranean Setting (CM 14), Groningen.

Swanepoel, M. G., 1993, "Ezekiel 16: Abandoned Child, Bride Adorned or Unfaithful Wife?", 84-104, en Davies, Ph. R. - Clines, D. J. A. (eds.), Among the Prophets: Language, Image and Structure in the Prophetic Writings (JSOT Suppl. Series), Sheffield.

Szlechter, E., 1958, Tablettes juridiques de la $1^{\text {re }}$ Dynastie de Babylone, $2^{\text {ème }}$ Partie, Paris.

Wunsch, C., 2003-2004, "Findelkinder und Adoption nach neubabylonischen Quellen", AfO 50, 174-244.

Yaron, R., 1965, "Varia on Adoption", Journal of Juristic Papyrology 15, 171-183.

DANiel Justel Vicente Universidad San Dámaso, Madrid 